\title{
Chemotherapy Versus Chemoradiation for Node-Positive Bladder Cancer: Practice Patterns and Outcomes from the National Cancer Data Base
}

\author{
Waqar Haque ${ }^{\mathrm{a}}$, Vivek Verma ${ }^{\mathrm{b}}$, E. Brian Butler ${ }^{\mathrm{c}}$ and Bin S. Teh ${ }^{\mathrm{c}, *}$ \\ ${ }^{a}$ Department of Radiation Oncology, CHI St Lukes Health, Houston, TX, USA \\ ${ }^{\mathrm{b}}$ Department of Radiation Oncology, University of Nebraska Medical Center, Omaha, NE, USA \\ ${ }^{\mathrm{c}}$ Department of Radiation Oncology, Houston Methodist Hospital, Houston, TX, USA
}

\begin{abstract}
.
Background: Management of clinically node-positive bladder cancer $(\mathrm{cN}+\mathrm{BC})$ is poorly defined; national guidelines recommend chemotherapy (CT) alone or chemoradiation (CRT).

Objective: Using a large, contemporary dataset, we evaluated national practice patterns and outcomes of CT versus CRT to elucidate the optimal therapy for this patient population.

Methods: The National Cancer Data Base (NCDB) was queried (2004-2013) for patients diagnosed with cT $\mathrm{ann}_{\mathrm{N}} \mathrm{N1}-3 \mathrm{M} 0 \mathrm{BC}$. Patients were divided into two groups: CT alone or CRT. Statistics included multivariable logistic regression to determine factors predictive of receiving additional radiotherapy, Kaplan-Meier analysis to evaluate overall survival (OS), and Cox proportional hazards modeling to determine variables associated with OS. Propensity score matching was performed to assess groups in a balanced manner while reducing indication biases.

Results: Of 1,783 total patients, 1,388 (77.8\%) underwent CT alone, and 395 (22.2\%) CRT. Although patients receiving CRT tended to be of higher socioeconomic status, they were more likely older ( $p=0.053$ ), higher T stage, N1 (versus N2) disease, squamous histology, and treated at a non-academic center $(p<0.05)$. Median overall survival (OS) was 19.0 months and 13.8 months $(p<0.001)$ for patients receiving CRT or CT, respectively. On Cox multivariate analysis, receipt of CRT was independently associated with improved survival $(p<0.001)$. Outcome improvements with CRT persisted on evaluation of propensity-matched populations $(p<0.001)$.

Conclusions: CRT is underutilized in the United States for $\mathrm{cN}+\mathrm{BC}$ but is independently associated with improved survival despite being preferentially administered to a somewhat higher-risk population.
\end{abstract}

Keywords: Bladder cancer, lymph node, radiation therapy, chemotherapy, chemoradiation

\footnotetext{
${ }^{*}$ Correspondence to: Bin S. Teh, Department of Radiation Oncology, Houston Methodist Hospital, Cancer Center and Research Institute, Weil Cornell Medical College, Houston, TX 77030, USA. Tel.: +1 713441 4800; Fax: +1 713441 449; E-mail: bteh@houstonmethodist.org.
}

\section{INTRODUCTION}

Clinically node-positive bladder cancer $(\mathrm{cN}+\mathrm{BC})$, an overall uncommon instance of newly-diagnosed $\mathrm{BC}$, carries a poor prognosis. It is thus categorized as stage IV disease, and as a result these 
patients have been largely excluded from seminal clinical trials utilizing radical cystectomy (RC) [1, 2]. According to the National Comprehensive Cancer Network (NCCN), standard of care for $\mathrm{cN}+\mathrm{BC}$ is either chemotherapy (CT) or chemoradiotherapy (CRT) [3].

The ambiguity in this recommendation is underscored by the lack of evidence regarding potential benefit of radiation therapy (RT) when added to systemic therapy for patients with $\mathrm{cN}+\mathrm{BC}$. There are several reasons to surmise that addition of local therapy may lead to superior tumor control and thus potentially improved outcomes. First, randomized trials of other neoplasms have shown that CT alone is inadequate to control gross disease; local therapy is thus necessary to provide durable local control, which may translate into survival benefits $[4,5]$. Second, analogous data in $\mathrm{cN}+$ prostate cancer, which faces a similar debate as $\mathrm{cN}+\mathrm{BC}$ to this extent, have shown benefits to the addition of RT to androgen deprivation therapy [6, 7]. Third, there have been numerous publications illustrating the benefit of local therapy (in the form of surgical nodal dissection) in $\mathrm{cN}+\mathrm{BC}$ [8-11]. Although those studies included only well-selected responders to CT (thus limiting applicability to all cases), they corroborated that a proportion of $\mathrm{cN}+\mathrm{BC}$ cases can indeed experience prolonged survival with aggressive local therapy.

Because $\mathrm{cN}+\mathrm{BC}$ is an overall uncommon circumstance with neither prospective nor high-volume retrospective data, this study was conducted using the large, contemporary dataset of the National Cancer Data Base (NCDB), in which we sought to evaluate practice patterns and outcomes in the management of this condition with respect to the two NCCNrecommended options, CT alone versus CRT.

\section{MATERIALS AND METHODS}

This study analyzed the NCDB, which is a joint project of the Commission on Cancer $(\mathrm{CoC})$ of the American College of Surgeons and the American Cancer Society, which consists of de-identified information regarding tumor characteristics, patient demographics, and patient survival for approximately $70 \%$ of the US population [12-15]. The NCDB contains information not included in the Surveillance, Epidemiology, and End Results database, including details regarding use of systemic therapy and radiation dose. The data used in the study were derived from a de-identified NCDB file (2004-2013 dataset). The American College of Surgeons and the CoC have not verified and are neither responsible for the analytic or statistical methodology employed nor the conclusions drawn from these data by the investigators. As all patient information in the NCDB database is de-identified, this study was exempt from institutional review board evaluation.

Inclusion criteria for this study were patients aged $>18$ years with newly-diagnosed $\mathrm{cT}_{\text {any }} \mathrm{cN} 1$ $3 \mathrm{cM} 0$ BC. For inclusion, patients required use of chemotherapy with or without RT and recorded follow up date. Exclusion criteria included receipt of cystectomy, subtherapeutic RT (defined as doses $<55$ Gray [3]), and treatment with palliative intent. Patients were then divided into two categories based on the type of treatment administered: CT alone or CRT.

All statistical tests were two-sided, with a threshold of $p<0.05$ for statistical significance, and were performed using STATA (version 14, College Station, TX). Fisher's exact or $\chi^{2}$ test analyzed categorical proportions between groups in the non-parametric and parametric settings, respectively. Multivariable logistic regression modeling was utilized to determine characteristics predictive of receiving additional RT. The Kaplan-Meier method was used for survival analysis, and comparisons between the two treatment paradigms were performed with the log-rank test for all patients. Overall survival (OS) was defined as the interval between the date of diagnosis and the date of death or last contact. Multivariate Cox proportional hazards modeling was additionally used to identify variables associated with OS in the entire cohort. An additional subset analysis was performed to compare OS between patients treated with CRT, single-agent chemotherapy ( $\mathrm{SCT}$ ), or multi-agent chemotherapy (mCT). Lastly, to account for indication bias, propensity-score matching was used to compare patients treated with CRT to those receiving treatment with $\mathrm{CT}$. Propensity matching is a method that creates quasicase/control pairs using a retrospective cohort in an effort to account for the recorded and unrecorded confounding variables [16-18]. Propensity scores were calculated by use of a multivariable logistic regression model with the dependent variable being receipt of treatment with CRT vs treatment with $\mathrm{CT}$ and the independent variables being age, sex, T/N stage, histology, Charlson-Deyo comorbidity score, facility type, and insurance status. Patients were matched 1:1 to avoid potential bias from many-to-one matching, and to 
ensure balance of the covariates within the two cohorts, standardized differences were assessed with a value $<0.1$ signifying an inconsequential imbalance [16-18]. Survival rates were compared between the two matched groups with the log-rank test.

\section{RESULTS}

A complete flow diagram of patient selection is provided in Fig. 1; 1,783 patients met study criteria. Of these, 1,388 (77.8\%) were treated with CT alone, and 395 (22.2\%) with CRT. Table 1 displays clinical characteristics of the analyzed patients. Of note, $\mathrm{cN} 1$, $\mathrm{cN} 2$, and $\mathrm{cN} 3$ disease was present in $794(44.5 \%)$, 790 (44.3\%), and 199 (11.2\%) patients. Figure 2 displays temporal trends of decreased frequency of CRT utilization as compared to CT alone.

Multivariable logistic regression analysis was performed to evaluate factors independently associated with undergoing CRT over CT alone (Table 2). Factors statistically associated with receipt of RT in addition to $\mathrm{CT}$ included increasing $\mathrm{T}$ stage, squamous cell carcinoma (when compared to urothelial) histology, treatment at a non-academic facility, and higher socioeconomic status $(p<0.05$ for all).

Median follow-up was 13.8 months (interquartile range, 7.9-27.4 months). Kaplan-Meier estimates of OS between groups are illustrated in Fig. 3A. The median OS in the CT only group was 13.8 months, whereas addition of RT to CT was associated with a survival improvement to 19.0 months $(p<0.001)$. On subset analysis, CRT was associated with a median OS improvement when compared to patients treated with either sCT (19.0 vs. 11.5 months, $p<0.001)$ or with $\mathrm{mCT}$ (19.0 vs. 14.0 months, $p<0.001$ ).

However, because the CT and CRT groups were imbalanced in terms of several variables, propensity matching was performed to evaluate OS between more balanced populations. When examining OS between both propensity matched cohorts (Fig. 3B), OS differences between cohorts persisted $(p<0.001)$.

Multivariate Cox proportional hazards modeling examining independent predictors of OS is displayed in Table 3. There were several factors associated with

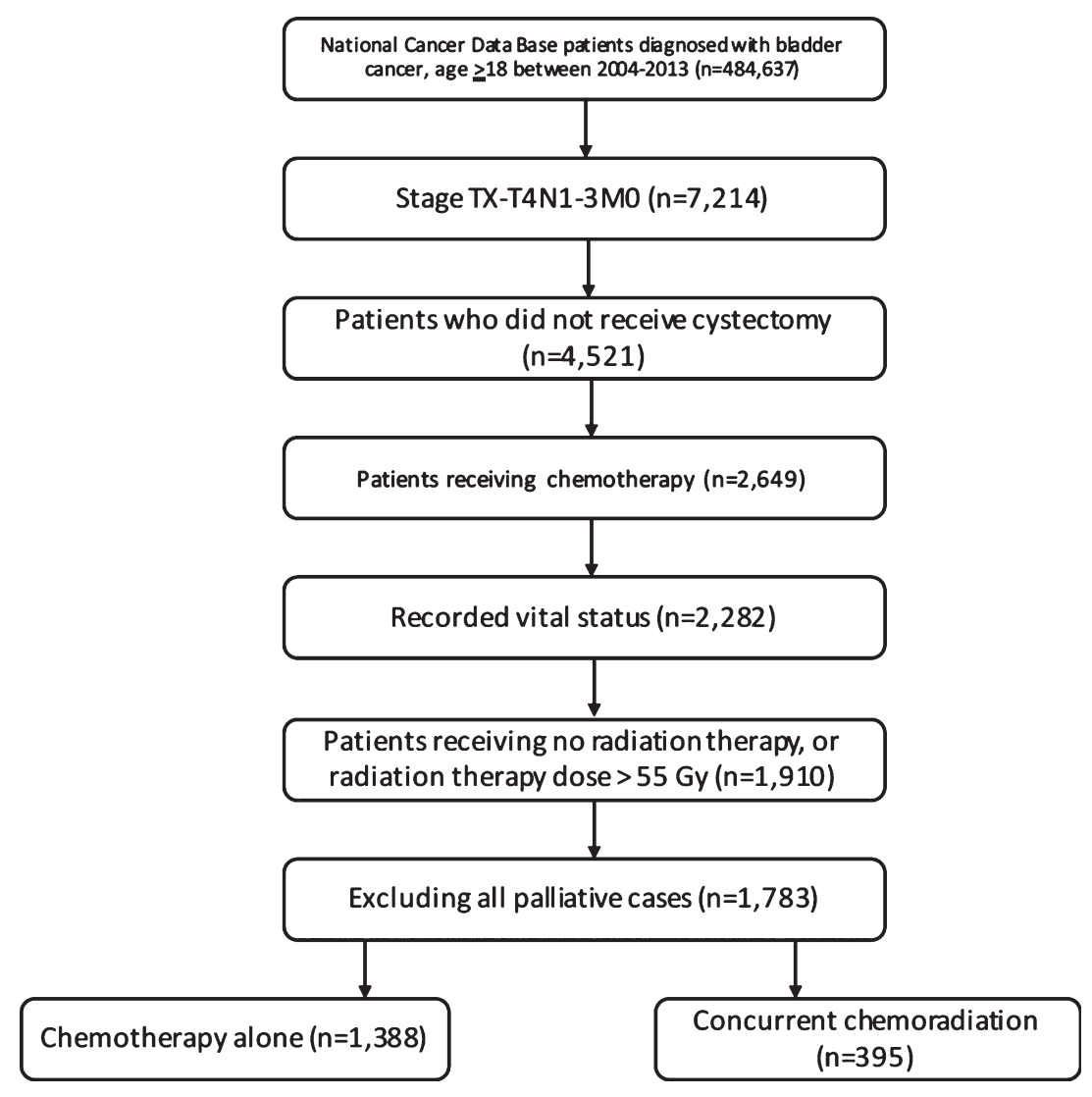

Fig. 1. Patient selection diagram. 
Table 1

Baseline characteristics of patients with bladder cancer receiving either chemotherapy alone or chemoradiation

\begin{tabular}{|c|c|c|c|}
\hline Characteristic & $\begin{array}{c}\text { Chemotherapy, } \\
n=1388(77.8 \%)\end{array}$ & $\begin{array}{l}\text { Chemoradiation, } \\
n=395(22.2 \%)\end{array}$ & $P$ value \\
\hline \multicolumn{4}{|l|}{$\overline{\text { Age }}$} \\
\hline$<65$ & $587(42.3 \%)$ & $120(30.4 \%)$ & \multirow[t]{2}{*}{$<0.001$} \\
\hline $65+$ & $801(57.7 \%)$ & $275(69.6 \%)$ & \\
\hline \multicolumn{4}{|l|}{ Sex } \\
\hline Male & $995(71.7 \%)$ & $289(73.2 \%)$ & \multirow[t]{2}{*}{0.564} \\
\hline Female & $393(28.3 \%)$ & $106(26.8 \%)$ & \\
\hline \multicolumn{4}{|l|}{ Race } \\
\hline White & $1167(84.1 \%)$ & $338(85.6 \%)$ & \multirow[t]{5}{*}{0.582} \\
\hline African American & $122(8.8 \%)$ & $36(9.1 \%)$ & \\
\hline Hispanic & $59(4.3 \%)$ & $11(2.8 \%)$ & \\
\hline Asian/ Native American/ Pacific Islander & $21(1.5 \%)$ & $7(1.8 \%)$ & \\
\hline Not recorded & $19(1.4 \%)$ & $3(0.8 \%)$ & \\
\hline \multicolumn{4}{|l|}{ T stage } \\
\hline $\mathrm{T} 1$ & $142(10.2 \%)$ & $23(5.8 \%)$ & \multirow[t]{5}{*}{0.001} \\
\hline $\mathrm{T} 2$ & $498(35.9 \%)$ & $141(35.7 \%)$ & \\
\hline $\mathrm{T} 3$ & $202(14.6 \%)$ & $86(21.8 \%)$ & \\
\hline $\mathrm{T} 4$ & $293(21.1 \%)$ & $84(21.3 \%)$ & \\
\hline Not recorded & $253(18.2 \%)$ & $61(15.4 \%)$ & \\
\hline \multicolumn{4}{|l|}{ N Stage } \\
\hline $\mathrm{N} 1$ & $590(42.5 \%)$ & $204(51.6 \%)$ & \multirow[t]{3}{*}{0.006} \\
\hline $\mathrm{N} 2$ & $637(45.9 \%)$ & $153(38.7 \%)$ & \\
\hline N3 & $161(11.6 \%)$ & $38(9.6 \%)$ & \\
\hline \multicolumn{4}{|l|}{ Histology } \\
\hline Urothelial carcinoma & $1198(86.3 \%)$ & $328(83.0 \%)$ & \multirow[t]{4}{*}{0.154} \\
\hline Squamous cell & $56(4.0 \%)$ & $22(5.6 \%)$ & \\
\hline Adenocarcinoma & $35(2.5 \%)$ & $7(1.8 \%)$ & \\
\hline Other & $99(7.1 \%)$ & $38(9.6 \%)$ & \\
\hline \multicolumn{4}{|l|}{ Charlson Deyo Score } \\
\hline 0 & $1051(75.7 \%)$ & $304(77.0 \%)$ & \multirow[t]{2}{*}{0.610} \\
\hline $1-2$ & $337(24.3 \%)$ & $91(23.0 \%)$ & \\
\hline \multicolumn{4}{|l|}{ Facility Type } \\
\hline Academic & $577(41.6 \%)$ & $120(30.4 \%)$ & \multirow[t]{2}{*}{$<0.001$} \\
\hline Non academic & $811(58.4 \%)$ & $275(69.6 \%)$ & \\
\hline \multicolumn{4}{|l|}{ Year of diagnosis } \\
\hline 2004-2008 & $488(35.2 \%)$ & $160(40.5 \%)$ & \multirow[t]{2}{*}{0.051} \\
\hline 2009-2013 & $900(64.8 \%)$ & $235(59.5 \%)$ & \\
\hline \multicolumn{4}{|l|}{ Insurance } \\
\hline Medicaid & $108(7.8 \%)$ & $24(6.1 \%)$ & \multirow[t]{5}{*}{0.001} \\
\hline Medicare & $750(54.0 \%)$ & $260(65.8 \%)$ & \\
\hline Private & $425(30.6 \%)$ & $87(22.0 \%)$ & \\
\hline Not insured & $60(4.3 \%)$ & $13(3.3 \%)$ & \\
\hline Other & $45(3.2 \%)$ & $11(2.8 \%)$ & \\
\hline \multicolumn{4}{|l|}{ Income } \\
\hline$<\$ 38000$ & $242(17.4 \%)$ & $44(11.1 \%)$ & \multirow[t]{5}{*}{0.013} \\
\hline$\$ 38000-\$ 47999$ & $336(24.2 \%)$ & $103(26.1 \%)$ & \\
\hline$\$ 48000-\$ 62999$ & $385(27.7 \%)$ & $111(28.1 \%)$ & \\
\hline$\$ 63000+$ & $392(28.2 \%)$ & $132(33.4 \%)$ & \\
\hline Not recorded & $33(2.4 \%)$ & $5(1.3 \%)$ & \\
\hline
\end{tabular}

worse OS: use of CT alone (when compared to CRT), female gender, T3 or T4 disease (when compared to T1), N3 status (when compared to N1), a Charlson Deyo comorbidity score of 1-2 (compared to a score of 0 ), or squamous cell histology (when compared to urothelial carcinoma) $(p<0.05$ for all). Of note, age and treatment facility type did not independently correlate with OS.

\section{DISCUSSION}

The management of $\mathrm{cN}+\mathrm{BC}$ is poorly defined, largely owing to its uncommon nature. There are numerous findings and reflections from this analysis of a contemporary national database, the largest of its kind to date. In the United States, CRT is underutilized as compared to CT alone, but was independently 


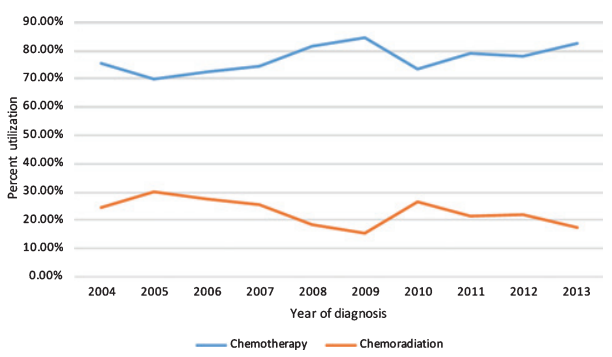

Fig. 2. Chemotherapy or chemoradiation utilization by year of diagnosis. associated with a survival benefit in these patients. These results have implications not only for patient management and counseling, but also for the NCCN recommendations.

Because CRT and CT alone are both recommended in the management of this population, the major goal of this study was to evaluate outcomes between both definitive treatments. The findings of independently higher OS with CRT, despite a substantially lower sample size (just $22.2 \%$ of patients received

Table 2

Characteristics predictive for addition of radiotherapy to chemotherapy on multivariable logistic regression analysis

\begin{tabular}{|c|c|c|c|}
\hline Characteristic & Odds Ratio & 95\% Confidence Interval & $P$ value \\
\hline \multicolumn{4}{|l|}{ Age } \\
\hline$<65$ & 1 (reference) & & \\
\hline $65+$ & 1.414 & $0.996-2.008$ & 0.053 \\
\hline \multicolumn{4}{|l|}{ Sex } \\
\hline Male & 1 (reference) & & \\
\hline Female & 0.928 & $0.714-1.207$ & 0.579 \\
\hline \multicolumn{4}{|l|}{ Race } \\
\hline White & 1 (reference) & & \\
\hline African American & 1.344 & $0.881-2.052$ & 0.170 \\
\hline Hispanic & 0.815 & $0.411-1.616$ & 0.558 \\
\hline Asian/ Native American/ Pacific Islander & 1.145 & $0.470-2.790$ & 0.766 \\
\hline Not recorded & 0.515 & $0.147-1.803$ & 0.299 \\
\hline \multicolumn{4}{|l|}{ T stage } \\
\hline $\mathrm{T} 1$ & 1 (reference) & & \\
\hline $\mathrm{T} 2$ & 1.740 & $1.067-2.837$ & 0.026 \\
\hline $\mathrm{T} 3$ & 2.834 & $1.682-4.775$ & $<0.001$ \\
\hline $\mathrm{T} 4$ & 1.869 & $1.115-3.132$ & 0.018 \\
\hline Not recorded & 1.642 & $0.962-2.803$ & 0.069 \\
\hline \multicolumn{4}{|l|}{ N Stage } \\
\hline $\mathrm{N} 1$ & 1 (reference) & & \\
\hline $\mathrm{N} 2$ & 0.713 & $0.557-0.912$ & 0.007 \\
\hline N3 & 0.731 & $0.489-1.093$ & 0.127 \\
\hline \multicolumn{4}{|l|}{ Histology } \\
\hline Urothelial carcinoma & 1 (reference) & & \\
\hline Squamous cell & 1.743 & $0.020-2.979$ & 0.042 \\
\hline Adenocarcinoma & 0.827 & $0.354-1.933$ & 0.661 \\
\hline Other & 1.442 & $0.961-2.163$ & 0.077 \\
\hline \multicolumn{4}{|l|}{ Charlson Deyo Score } \\
\hline 0 & 1 (reference) & & \\
\hline $1-2$ & 0.868 & $0.659-1.142$ & 0.311 \\
\hline \multicolumn{4}{|l|}{ Facility Type } \\
\hline Academic & 1 (reference) & & \\
\hline Non academic & 1.643 & $1.282-2.107$ & $<0.001$ \\
\hline \multicolumn{4}{|l|}{ Year of diagnosis } \\
\hline 2004-2008 & 1 (reference) & & \\
\hline 2009-2013 & 0.821 & $0.642-1.050$ & 0.115 \\
\hline \multicolumn{4}{|l|}{ Insurance } \\
\hline Medicaid & 1 (reference) & & \\
\hline Medicare & 1.128 & $0.639-1.992$ & 0.678 \\
\hline Private & 0.791 & $0.469-1.334$ & 0.379 \\
\hline Not insured & 1.107 & $0.515-2.379$ & 0.795 \\
\hline Other & 0.899 & $0.388-2.084$ & 0.804 \\
\hline \multicolumn{4}{|l|}{ Income } \\
\hline$<\$ 38000$ & 1 (reference) & & \\
\hline$\$ 38000-\$ 47999$ & 1.764 & $1.172-2.653$ & 0.006 \\
\hline$\$ 48000-\$ 62999$ & 1.648 & $1.103-2.461$ & 0.015 \\
\hline$\$ 63000+$ & 2.012 & $1.345-3.010$ & 0.001 \\
\hline Not recorded & 0.718 & $0.259-1.987$ & 0.524 \\
\hline
\end{tabular}



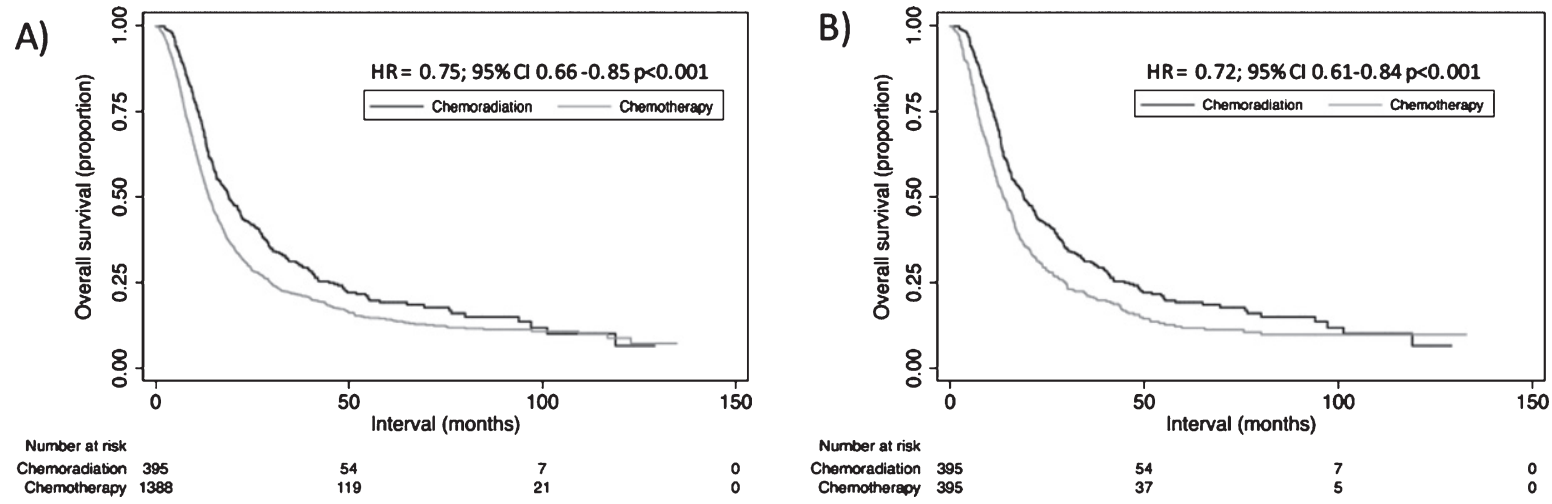

Fig. 3. Kaplan-Meier overall survival curves comparing those receiving chemoradiation versus chemotherapy alone (A), and in the propensitymatched population $(\mathrm{B})$.

CRT), is even more noteworthy for one major reason described in other work [19]. As compared with CT alone, RT was likely added for "higher-risk" disease with presumably some degree of poor-prognostic features. Indeed, although CRT was utilized in older (65+years old, $p=0.053)$ individuals with more advanced T- classification, and non-urothelial histology, addition of radiotherapy to CT independently associated with improved survival in this "higherrisk" cohort. This further suggests that, in an evenly matched population, the OS benefit with the addition of RT to CT may be even greater than the absolute 5.2 month median OS benefit described here.

In light of the aforementioned surgical series and other data [8-11], CRT may be advantageous because development of a (pathologic) complete response has been linked with improved prognosis. This likely reflects the presence of favorable tumor biology, but efforts to increase the (pathologic) complete response rate are nevertheless warranted and are being attempted in other neoplasms [20]. Furthermore, more aggressive therapy along with CT may allow well-selected responders to undergo $\mathrm{RC}$ and potentially eliminate all traces of gross disease, which as mentioned above have resulted in good outcomes. In a NCDB study of $\mathrm{cN}+\mathrm{BC}$ (that did not evaluate radiotherapy), addition of neoadjuvant $\mathrm{CT}$ to $\mathrm{RC}$ was associated with a survival improvement over RC alone, likely relating to well-selected patients but also potentially owing to better sterilization of existing microscopic disease prior to gross total resection [21]. Finally, it has been documented in other disease sites that $\mathrm{CT}$ alone is unable to eradicate gross disease [4, 5]. The results of this study are very much in line with those of prostate cancer, in which the addition of RT to systemic therapy has been demonstrated to offer substantial survival benefits in patients with node positive disease $[6,7]$.

From this study, an unresolved issue is administration of CT and RT sequentially versus concurrently. A caveat of our study is the lack of stratification in sequencing of both modalities, and to this extent further work must be performed. Additionally, it is difficult to address herein whether $\mathrm{cN} 1, \mathrm{cN} 2$, or $\mathrm{cN} 3$ patients benefit from CRT, owing to sample size issues in analyzing sub-cohorts and especially the low numbers of $\mathrm{cN} 3$ patients.

Optimal radiotherapy techniques in $\mathrm{cN}+\mathrm{BC}$ are not well-defined apart from small series [22]. Although three-dimensional techniques are clearly preferred, we propose that inverse-planned techniques such as intensity-modulated radiotherapy (IMRT) or volumetric-modulated arc therapy (VMAT) may be uniquely suited for $\mathrm{cN}+\mathrm{CRT}$. This largely centers on the ability to perform simultaneous integrated boosting of grossly involved lymph nodes (and gross bladder disease) while delivering tumoricidal doses to non-clinically involved areas of lymphatics, and low doses to surrounding organs-atrisk. In general BC cohorts, both IMRT and VMAT display lower bowel doses over three-dimensional conformal radiotherapy (3DCRT) [23]. Moreover, IMRT is also associated with low rates of toxicities, potentially as a result of these dosimetric advantages over 3DCRT [24-27]. However, a caveat to utilizing IMRT in BC relates to interfractional changes in organ motion, especially with regard to bladder filling. For this reason, image-guided radiotherapy is also recommended whenever possible.

There are several limitations of this investigation. Selection biases in this and any retrospective study are readily recognized. Another major caveat to these 
Table 3

Cox multivariate analysis of factors predictive of overall survival in the entire cohort

\begin{tabular}{|c|c|c|c|}
\hline Characteristic & HR & $95 \% \mathrm{CI}$ & $P$ value \\
\hline \multicolumn{4}{|l|}{ Treatment group } \\
\hline Chemotherapy & 1 (reference) & & \\
\hline Chemoradiation & 0.718 & $0.628-0.819$ & $<0.001$ \\
\hline \multicolumn{4}{|l|}{ Age } \\
\hline$<65$ & 1 (reference) & & \\
\hline $65+$ & 1.094 & $0.935-1.280$ & 0.264 \\
\hline \multicolumn{4}{|l|}{ Sex } \\
\hline Male & 1 (reference) & & \\
\hline Female & 1.287 & $0.143-1.448$ & $<0.001$ \\
\hline \multicolumn{4}{|l|}{ Race } \\
\hline White & 1 (reference) & & \\
\hline African American & 0.989 & $0.814-1.201$ & 0.913 \\
\hline Hispanic & 0.626 & $0.455-0.861$ & 0.004 \\
\hline Asian/ Native American/ Pacific Islander & 0.550 & $0.329-0.920$ & 0.023 \\
\hline Not recorded & 1.054 & $0.635-1.749$ & 0.840 \\
\hline \multicolumn{4}{|l|}{ T stage } \\
\hline $\mathrm{T} 1$ & 1 (reference) & & \\
\hline $\mathrm{T} 2$ & 1.141 & $0.928-1.403$ & 0.211 \\
\hline T3 & 1.349 & $1.073-1.700$ & 0.011 \\
\hline $\mathrm{T} 4$ & 1.765 & $1.418-2.200$ & $<0.001$ \\
\hline Not recorded & 1.250 & $0.995-1.571$ & 0.055 \\
\hline \multicolumn{4}{|l|}{ N Stage } \\
\hline N1 & 1 (reference) & & \\
\hline $\mathrm{N} 2$ & 1.046 & $0.933-1.172$ & 0.439 \\
\hline $\mathrm{N} 3$ & 1.365 & $1.138-1.636$ & 0.001 \\
\hline \multicolumn{4}{|l|}{ Histology } \\
\hline Urothelial carcinoma & 1 (reference) & & \\
\hline Squamous cell & 1.852 & $1.425-2.408$ & $<0.001$ \\
\hline Adenocarcinoma & 0.845 & $0.601-1.188$ & 0.333 \\
\hline Other & 1.446 & $1.191-1.756$ & $<0.001$ \\
\hline \multicolumn{4}{|l|}{ Charlson Deyo Score } \\
\hline 0 & 1 (reference) & & \\
\hline $1-2$ & 1.242 & $1.100-1.407$ & 0.001 \\
\hline \multicolumn{4}{|l|}{ Facility Type } \\
\hline Academic & 1 (reference) & & \\
\hline Non academic & 1.041 & $0.931-1.163$ & 0.485 \\
\hline \multicolumn{4}{|l|}{ Year of diagnosis } \\
\hline $2004-2008$ & 1 (reference) & & \\
\hline 2009-2013 & 0.892 & $0.795-1.002$ & 0.053 \\
\hline \multicolumn{4}{|l|}{ Insurance } \\
\hline Medicaid & 1 (reference) & & \\
\hline Medicare & 0.960 & $0.748-1.232$ & 0.751 \\
\hline Private & 0.887 & $0.709-1.110$ & 0.296 \\
\hline Not insured & 1.068 & $0.767-1.456$ & 0.697 \\
\hline Other & 1.083 & $0.748-1.567$ & 0.673 \\
\hline \multicolumn{4}{|l|}{ Income } \\
\hline$<\$ 38000$ & 1 (reference) & & \\
\hline$\$ 38000-\$ 47999$ & 0.992 & $0.834-1.180$ & 0.929 \\
\hline$\$ 48000-\$ 62999$ & 1.062 & $0.896-1.258$ & 0.491 \\
\hline$\$ 63000+$ & 0.949 & $0.797-1.129$ & 0.554 \\
\hline Not recorded & 1.672 & $1.165-2.399$ & 0.005 \\
\hline
\end{tabular}

data is the lack of confirmation whether patients had histologic corroboration of $\mathrm{cN}+$ disease. However, as acknowledged by the NCCN, this is not feasible in many cases [3]; to this extent, although it is unknown how many patients had positron emission tomography-based initial workup, it may be useful in cases for which biopsy is not feasible. Next, the NCDB does not keep track of several noteworthy variables, such as specific CT agents and number of cycles completed, RT fields (including nodal volumes), reasons for a particular treatment, immune/biologic therapies, and salvage treatment, 
which could all confound conclusions presented herein. It also does not record other endpoints such as tolerance of therapy (including premature cessation of CT), cancer-specific survival, and local/regional control. Nevertheless, the caveats herein do not obviate the need for further investigation to corroborate these conclusions.

\section{CONCLUSIONS}

This is the largest study to date examining the practice patterns and outcomes for patients with $\mathrm{cN}+\mathrm{BC}$. The results suggest that although bimodality therapy is currently underutilized, and more often given to "higher-risk" patients, the addition of radiation therapy to chemotherapy may improve survival for patients with $\mathrm{cN}+\mathrm{BC}$. Other investigations are recommended to further elucidate the optimal treatment paradigm for patients with $\mathrm{cN}+\mathrm{BC}$.

\section{DECLARATION}

There are no acknowledgements. There was no funding for this study. This study has not been presented or published in part or full form elsewhere. All authors declare no conflicts of interest.

\section{DISCLAIMERS}

None. This has never been presented/published before in any form. All authors declare that conflicts of interest do not exist.

\section{FUNDING}

There was no research support for this study.

\section{REFERENCES}

[1] Grossman HB, Natale RB, Tangen CM, et al. Neoadjuvant chemotherapy plus cystectomy compared with cystectomy alone for locally advanced bladder cancer. N Engl J Med 2003;349:859-66.

[2] Sherif A, Holmberg L, Rintala E, et al. Neoadjuvant cisplatinum based combination chemotherapy in patients with invasive bladder cancer: A combined analysis of two Nordic studies. Eur Urol 2004;45:297-303.

[3] National Comprehensive Cancer Network. Bladder cancer. Version 5.2017. https://www.nccn.org/professionals/ physician_gls/pdf/bladder.pdf Accessed August 30, 2017.

[4] Perry MC, Herndon III JE, Eaton WL, Green MR. Thoracic radiation therapy added to chemotherapy for small-cell lung cancer: An update of cancer and leukemia group B study 8083. J Clin Oncol 1998;16:2466-7.
[5] Jaeckle K, Vogelbaum M, Ballman K, et al. CODEL (Alliance-N0577; EORTC-26081/22086; NRG-1071; NCIC-CEC-2): Phase III Randomized Study of RT vs. RT+TMZ vs. TMZ for Newly Diagnosed 1p/19q-Codeleted Anaplastic Oligodendroglial Tumors. Analysis of Patients Treated on the Original Protocol Design (PL02.005). Neurology 2016;86:Supp1.PL02.005.

[6] Tward JD, Kokeny KE, Shrieve DC. Radiation therapy for clinically node-positive prostate adenocarcinoma is correlated with improved overall and prostate cancer-specific survival. Pract Radiat Oncol 2013;3:234-40.

[7] Rusthoven CG, Carlson JA, Waxweiler TV, et al. The impact of definitive local therapy for lymph node-positive prostate cancer: A population-based study. Int J Radiat Oncol Biol Phys 2014;88:1064-73.

[8] Herr HW, Donat SM. Outcome of patients with grossly node positive bladder cancer after pelvic lymph node dissection and radical cystectomy. J Urol 2001;165:62-4.

[9] Zargar-Shoshtari K, Zargar H, Lotan Y, et al. A MultiInstitutional Analysis of Outcomes of Patients with Clinically Node Positive Urothelial Bladder Cancer Treated with Induction Chemotherapy and Radical Cystectomy. J Urol 2016;195:53-9.

[10] Ho PL, Willis DL, Patil J, et al. Outcome of patients with clinically node-positive bladder cancer undergoing consolidative surgery after preoperative chemotherapy: The M.D. Anderson Cancer Center Experience. Urol Oncol 2016;34:59.e1-8.

[11] Moschini M, Morlacco A, Briganti A, et al. Clinical Lymphadenopathy in Urothelial Cancer: A Transatlantic Collaboration on Performance of Cross-sectional Imaging and Oncologic Outcomes in Patients Treated with Radical Cystectomy Without Neoadjuvant Chemotherapy. Eur Urol Focus 2016;doi: 10.1016/j.euf.2016.11.005.

[12] Bilimoria K, Stewart A, Winchester D, Ko C. The National Cancer Data Base: A powerful initiative to improve cancer care in the United States. Ann Surg Oncol 2008;15: 683-90.

[13] Haque W, Verma V, Fakhreddine M, et al. Addition of chemotherapy to definitive radiotherapy for IB1 and IIA1 cervical cancer: Analysis of the National Cancer Data Base. Gynecol Oncol 2017;144:28-33.

[14] Haque W, Verma V, Butler EB, Teh BS. Patterns of care and outcomes of multi-agent versus single-agent chemotherapy as part of multimodal management of low grade glioma. J Neurooncol 2017; doi: 10.1007/s11060-017-2443-7

[15] Moreno AC, Verma V, Hofstetter WL, Lin SH. Patterns of Care and Treatment Outcomes of Elderly Patients With Stage I Esophageal Cancer: Analysis of the National Cancer Data Base. J Thorac Oncol 2017; doi: 10.1016/j.jtho.2017.04.004

[16] Austin PC. Statistical criteria for selecting the optimal number of untreated subjects matched to each treated subject when using many-to- one matching on the propensity score. Am J Epidemiol 2010;172:1092-7.

[17] Rosenbaum PR, Rubin DB. The central role of the propensity score in observational studies for causal effects. Biometrika 1983;70:15.

[18] Austin PC, Gootendorst P, Anderson GM. A comparison of the ability of different propensity score models to balance measured variables between treated and untreated subjects: A Monte Carlo study. Stat Med 2007;26:734-53.

[19] Verma V, McMillan MT, Grover S, Simone CB 2nd. Stereotactic Body Radiation Therapy and the Influence of Chemotherapy on Overall Survival for Large 
( $\geq 5$ Centimeter) Non-Small Cell Lung Cancer. Int J Radiat Oncol Biol Phys 2017;97:146-54.

[20] Suntharalingam M, Paulus R, Edelman MJ, et al. RTOG 0229: A Phase II Trial of Neoadjuvant Therapy with Concurrent Chemotherapy and Full Dose Radiotherapy (XRT) followed by Resection and Consolidative Therapy for LANSCLC. Int J Radiat Oncol Biol Phys 2010;78:S111.

[21] Galsky MD, Stensland K, Sfakianos JP, et al. Comparative Effectiveness of Treatment Strategies for Bladder Cancer With Clinical Evidence of Regional Lymph Node Involvement. J Clin Oncol 2016;34:2627-35.

[22] Fackrell DG, Ford D, Chetiyawardana S, et al. The delivery of radical radiotherapy to the bladder and pelvis in nodepositive (N1) bladder cancer: A five patient case series. BJR Case Rep 2016;2:20160102.

[23] Foroudi F, Wilson L, Bressel M, et al. A dosimetric comparison of $3 \mathrm{D}$ conformal vs intensity modulated vs volumetric arc radiation therapy for muscle invasive bladder cancer. Radiat Oncol 2012;7:111.
[24] Hsieh CH, Chung SD, Chan PH, et al. Intensity modulated radiotherapy for elderly bladder cancer patients. Radiat Oncol 2011;6:75.

[25] Meijer GJ, van der Toorn PP, Bal M, et al. High precision bladder cancer irradiation by integrating a library planning procedure of 6 prospectively generated SIB IMRT plans with image guidance using lipiodol markers. Radiother Oncol 2012;105:174-9.

[26] Turgeon GA, Souhami L, Cury FL, et al. Hypofractionated intensity modulated radiation therapy in combined modality treatment for bladder preservation in elderly patients with invasive bladder cancer. Int J Radiat Oncol Biol Phys 2014;88:326-31.

[27] Kollmeier MA, Thakker N, Zelefsky MJ, et al. ImageGuided Intensity Modulated Radiation Therapy (IMRT) for Bladder Cancer: Toxicity and Early Outcomes. Int J Radiat Oncol Biol Phys 2014;90:S463. 